\title{
Compensation for Personal Injuries: A Review of Recent Legal and Insurance Developments in the $\mathrm{UK}^{*}$
}

\author{
by Roger Bowles**
}

\section{Damages for personal injuries}

\section{Introduction}

The purpose of the first part of this paper is to explore the principles which govern the award of damages for personal injury under English law. We show here that the traditional judicial approach to damages has a natural interpretation as a means of computing the present value of expected loss. The purpose of the second part is to apply the model to the debate going on in England at present as to how best the law in this area may be reformed in the light of the development of 'structured settlements'. The rapid growth of structuring is explained by reference to the advantages current arrangements (most notably the agreement struck between the Inland Revenue and the Association of British Insurers as to the tax treatment of annuities) offer to insurers, although we do not offer a full public choice treatment of the development of policy in this area.

The economic model of accident law familiar from the literature is usually based on the assumption that judges make awards of damages which reflect accurately the plaintiff's losses (see for example Shavell, 1987). Claims about the efficiency of negligence rules rely on such assumptions, and yet much of the literature concerns itself with matters of detail about the structure of the liability rules and ignores the question of whether courts, in practice, are making reliable estimates of losses.

The present paper has narrower ambitions than much of the efficiency-based literature. It is concerned more with valuation procedures than with the efficiency properties of the amounts of damages which result. It seems relatively clear that English judges are

* The discussant of this paper at the Geneva conference, Chris Curran, helpfully pointed out an algebraic error in the original draft. For this and for other perceptive comments I am gratcful to him. I would also like to thank other conference participants, particularly Samual Rea, and the editors of this issue of Geneva Papers for useful comments and criticisms. Remaining errors are my own responsibility. Although this work is a development of research commissioned initially for the English Law Commission it in no way reflects the views of the Commission.

Revised draft of a paper presented at Geneva Association / EALE Conference on the Law and Economics of Insurance, Geneva, April 1993.

${ }^{* *}$ School of Social Scienccs, University of Bath, Bath, BA2 7AY, UK. 
seeking to make awards which reflect as closely as possible the Present Value of losses. Thus we do not follow the lead of Rea (1990) in seeking to explore the role of taxation and its influence on the capacity of a negligence rule to meet various objectives in a welfare maximisation setting. We are concerned with the rather different task of characterising the way English judges quantify awards of damages and identifying circumstances in which these procedures may fail to approximate the present value of plaintiffs' losses.

\section{The traditional English judicial approach}

\subsection{Outline of the method}

It is convenient to begin by setting up a model which characterizes the approach taken under English law to the determination of damages for personal injury. The amount of damages is normally computed (or at least quoted) as the product of the average expected annual loss and a 'Multiplier'. The essence of the approach can be captured with a simple equation:

$$
\mathrm{D}=\mathrm{A} \cdot \mathrm{M}
$$

where

$\mathrm{D}$ is a lump sum of damages

$A$ is the annual loss (before tax) to be replaced: [in English law it is referred to as the 'Multiplicand']

$\mathbf{M}$ is referred to as the 'Multiplier'.

The annual loss $\mathrm{A}$ is measured in real terms and assumed, for simplicity at this stage, to remain constant. The 'Multiplier' $M$, in the simplest model, reflects two factors namely the real rate of interest (also assumed constant for the moment) at which losses are to be discounted and the time horizon over which losses are expected to last. Since:

$$
D=\Sigma_{t=1}^{n} A /(1+r)^{n}
$$

where

$r$ is the real interest rate

$t(=1,2, \ldots, n)$ indexes time, with horizon $n$,

and, from (1), $M=D / A$ then we can write an expression for the Multiplier as follows:

$$
M=1 /(1+r)^{n}
$$

Further refinement is possible. Under English law the Multiplier is adjusted to account for the vicissitudes of life. In actuarial terms, the probability of the plaintiff's survival decays over time, so we could make an appropriate adjustment as follows:

$$
D=\Sigma_{t=1}^{n} A p_{t} /(1+r)^{n}
$$

where $p_{t}$ measures the probability of surviving to period $t$ and, by definition, $p_{t} \leq p_{t-1}$.

It is conventional for the life risk to be considered jointly with the choice of time horizon. The judge compounds the two to arrive at an appropriate multiplier:

$$
M=\sum_{t} p_{t} /(1+r)^{n}
$$

The resulting number is then simply multiplied by the annual loss $A$ to produce a lump sum of damages $D$. From a practical point of view this is a straightforward procedure, since actuaries have computed tables by age and sex which make allowance for the life risks. All that is needed is for the length of the horizon and the discount rate to be chosen and a number can be read off tables for the Multiplier. 
Thus, in principle, one could argue that the judicial approach, despite its quaint terminology, involves the kind of present value calculation the efficiency model would require.

\section{Criticisms of the method}

Achievement of a level of damages corresponding with the Present Value of loss nevertheless requires that one choose sensible values for insertion into the formula. There have been a number of criticisms of the conventions applied under English law. The criticisms have really been of two kinds: first, that inappropriate values have been chosen for one or other of the formula's components and secondly that insufficient attention has been paid to interactions between the various components. We consider in the next two sections the choice of discount rate and the treatment of contingencies, two of the key components of the formula. We then look at two further difficulties for the computation of damages consistent with Present Value.

\subsection{Choice of discount rate}

The conventional discount rate applied is English courts is between 4 and $5 \%$, rather higher than the figure of around $2.5 \%$ applied in the US. This, of course, has to be taken as a proxy for the real rate of interest since losses are being measured in real terms. From an empirical perspective the question is whether this represents a reasonable approximation to rates available to investors.

This turn out to be quite a complex matter because one needs to ensure that the interest rate is computed in a way which is consistent with the yields available on the sorts of financial instruments plaintiffs could use to offset their losses. Expected inflation plays an important part in determining nominal yields and thus will be crucial in influencing yields on longdated instruments. But it is the time path of expected inflation as well as its current level which is important, with the result that it is insufficient to compute the real interest rate by subtracting the current rate of price inflation from the nominal yield on long-dated securities (Arak and Kreicher, 1985; Levin and Copeland, 1992).

The consensus appears to be that an appropriate real rate can be approximated by the gross redemption yield available on (UK) Index-Linked Government Stocks of an appropriate maturity (say, 15 years) using a 'reasonable' estimate of likely inflation. On the basis of average annual yields on such stocks since they were first issued in 1981 an appropriate figure would be somewhere between $3.5 \%$ and $4 \%$, although the yield has been on a slight upward trend, suggesting that $4 \%$ might be closer than $3.5 \%$. The net result then is that the courts are probably applying a discount rate which on average is reasonable.

\subsection{Contingencies}

The Multiplier needs to reflect the probabilities with which the plaintiff could have been expected to experience loss over future time periods. It should therefore reflect contingencies such as the increasing probability of death with age, differences between male and female mortality rates and so on. It should reflect also things such as the prospect of job promotions, redundancy and other labour market contingencies. Actuaries are quite accustomed to making these sorts of calculations, and indeed there are actuarial tables published in the standard work on damages employed by practicioners (Kemp and Kemp, 8-029).

Judges, by contrast, are not inclined to rely either on actuarial tables or evidence from actuaries in court. By virtue (presumably) of superior intuition and knowledge of the world 
judges are able to avoid the drawback that '... [the actuarial method] may ensnare one into treating as virtual certainties what in truth are mere chances' (dictum of Edmund Davies, L.J. in the 1972 case of Mitchell v. Mulholland, reaffirmed in the Auty case of 1981). Lord Pearson, in the 1971 case of Taylor v. O'Connor echoes the same view and argues that: '... the experience of practicioners and judges in applying the normal method is the best primary basis for making assessments'. The judges clearly feel that they have a capacity to make a more precise prognosis of loss for the plaintiff than can be had from statistical tables which refer to classes of peoplc. For further criticism of the judicial attitude towards the actuarial approach, see Prevett (1986). If judges are trying in their judgments to compute the present value of losses then one would expect a more positive attitude towards actuarial evidence.

\subsection{Compounding problems}

The second kind of criticism of the judicial method of computing damages is that there are cases when calculation of the multiplier involves an element of 'double counting'. There seem to be cases where the judges have reduced the length of the horizon over which loss is experienced at the same time as making greater allowance for mortality risk.

An illustration of this can be found in the judgment of Lord Scarman in Lim v. Camden Health Authority [1980] A.C. 174. To give an idea of how judges reach the multiplier we begin with Lord Scarman's commentary in respect of the cost of care: "Her expectation of life, according to the tables, will be in the order of a further 37 years. In this case I will make a substantial discount because of the accelerated payment, some reduction for the contingency that she will not reach the average age... Balancing these elements as best I can, I find the appropriate multiplier for the period of future care in England to be 11."

In relation to the loss of future earnings and pension in a later part of his speech Lord Scarman makes the following, rather puzzling assertion:

“... Dr Lim's expectation of life after her injury is substantially as it was before her injury... Nevertheless [...] the contingency of an earlier death is plainly more likely after than it was before her injury."

The treatment of mortality and other contingencies seems thus to be a rather weak link in the chain if one is to make the argument that judges make awards of damages which are systematically based on the Present Value of losses.

\subsection{Other criticisms of procedures for quantifiying damages}

At a rather different level it has been argued by some authors that the amount awarded in court is not, in any event, the relevant benchmark. The great bulk of personal injuries cases are settled out-of-court with the result that one needs to think about the implications of the level of judicial damage awards in terms of their implications for out-of-court settlements. Court awards, it is argued, should reflect the risks run by the plaintiff in insisting that a court determine the final award rather than it being settled in out-of-court negotiation; see Phillips et al. (1975).

Plaintiffs in personal injury cases are usually one-shot players whereas the defendant is usually an insurance company engaged in a repeated game where reputational effects may be important; see Hirshleifer and Riley (1992) for a review of the economics of reputation building and Genn (1987) for an empirical analysis in the context of personal injuries in 
England. The insurance company is better able to diversify the risk associated with a single claim than is the plaintiff, who may in any event be more averse to risk. The capacity of insurance companies in out-of-court negotiations to capitalize on their different attitude to risk is enhanced by the payment-into-court system for reasons I have discussed elsewhere ; Bowles, 1981.

\section{Structured settlements}

In recent years there has been a move in England in cases of damages for personal injury towards the US practice of 'structuring' settlements. The essence of structuring is that the award of damages takes the form of a bundle of annuities rather than a single lump sum. In this section we will emplore first how the effects of structuring can be incorporated into our algebraic model. We will argue then that structuring represents an opportunity for the courts to find a way out of a serious problem of internal inconsistency which might otherwise dog damage awards.

Two key events have contributed to the development of structuring. First, since 1981 the UK Government has issued indexed bonds of varying maturities which offered indexed income and capital repayment. This has made it much easier for insurers to hedge inflation risks. Secondly, an agreement was reached in 1987 between the Association of British Insurers and the Inland Revenue under which income tax is no longer payable on that part of the return from an annuity which is deemed to represent capital repayment. The 'pure income' element of annuity income continues to be taxable.

\subsection{The effect of structuring}

From the plaintiff's perspective the advantage of structuring is said to be first that the plaintiff receives more lenient tax treatment of the proceeds of a structured settlements and secondly that it helps ensure that the plaintiff has in place a set of investments appropriate for replacing the lost income stream.

An efficiency approach would ignore the second of these arguments on the grounds that it is paternalistic. The plaintiff will be indifferent between a lump sum and a bundle of annuities with the same present value. In England there is a tendency to give some weight to the paternalist approach if only on 'bounded rationality' grounds. The Pearson Commission which investigated Personal Injuries in the 1970's considered proposing a system of periodic payments to replace lump sum damages in part because of their finding that only $5 \%$ of recipients of lump sum invested any of the proceeds (Pearson Commission, 1978).

The tax advantages for plaintiffs of structured settlements are a rather different matter. Before considering the question of the incidence of the benefits of the tax concessions we set out a model which illustrates the extent of the advantage.

In our earlier terminology $D$ represents the level of damages appropriate to pre-tax losses of $A$ per annum. We will abstract here from the question of whether the courts do, in fact, base damages on pre-tax rather than post-tax losses. From an economic perspective it is only really possible to make sense of what follows if we start from pre-tax, or gross, income. The implicit assumption is that annuity income generated from an actuariallyfair policy will attract the same level of tax as the plaintiff would have paid on pre-tax earnings $A$. 
Suppose, for the moment, that the plaintiff receives the same award of damages, $D$, as previously. The value to the plaintiff of the change in the tax regime can be computed by comparing post tax income before and after the change:

$$
\text { gain, } G=\{A[1-x+M x / n]-A[1-x]\} / A[1-x]
$$

thus :

$$
G=M x / n[1-x]
$$

The values of $G$ for various values of $M, x$ and $n$ are tabulated in Table 1. The Table indicates that the gains are quite

Table 1:

Value of tax concession when capital repayment element of annuity income is tax exempt

\begin{tabular}{|c|c|cc|}
\hline $\begin{array}{c}\text { Years of } \\
\text { loss } \\
n\end{array}$ & $\begin{array}{c}\text { Multiplier } \\
(r=4 \%) \\
M\end{array}$ & $x-0.25$ & Tax rate \\
\hline 5 & 4.4518 & 0.297 & $x=0.40$ \\
10 & 8.1109 & 0.270 & 0.593 \\
15 & 11.1183 & 0.247 & 0.541 \\
20 & 13.5903 & 0.226 & 0.494 \\
\hline
\end{tabular}

significant in all cases and that the gain is worth twice as much for those paying tax at the higher rate of $40 \%$. This latter result occurs because the term $x /[1-x]$ doubles as $x$ rises from .25 to .4 . The value of the tax concession decreases with the time horizon of loss since the capital repayment component is being more thinly spread. From the court's perspective these gains might be viewed with some alarm. The court is applying the principle of 'restitutio in integrum' - making whole the plaintiff's loss. If annuity proceeds are more generously taxed did this not ought to mean that the amount of damages awarded should be reduced accordingly? This could be achieved either through adjusting the size of the Multiplier $M$ or the annual loss $A$.

Now define a new level of damages $D^{\prime}$ where $D^{\prime}$ represents the cost of an annuity which gives the same post-tax income as previously, tax allowance having been made against that part of the return from the annuity which represents a capital repayment. For simplicity we assume a linear income tax payable at rate $x$ on all taxable income.

Under the new 'tax deductible capital repayment' arrangement the plaintiff will need a smaller lump sum to replace post-tax losses than previously. Denoting gross receipts under the 'new' annuity as $A^{\prime}$ ' (to correspond with the new sum of damages $D$ ') we may write:

$$
A[1-x]=A^{\prime}-\left[A^{\prime}-D^{\prime} / n\right] x
$$

Since nothing has happened to disturb the value of the multiplier $M$, we can exploit the relationship between the sum of damages, the multiplier and the annual loss to substitute for the term $D \%$ as follows:

$$
A[1-x]=A^{\prime}-\left[A^{\prime}-A^{\prime} \cdot M / n\right] x
$$


Which can be rearranged to give :

$$
A[1-x]=A^{\prime}[1-x+M x / n]
$$

Since the multiplier $M$ remains the same under the tax change, the ratio $D / D$ ' is the same as the ratio $A / A^{\prime}$ because $M=D / A=D^{\prime} / A^{\prime}$ and so:

$$
A / A^{\prime}=D / D^{\prime}=[1-x[1-M / n]] /[1-x]
$$

This finding can be used in various ways. One obvious way is to derive from it an expression for the reduction in the lump sum award of damages needed to restore the plaintiff's after tax earnings to the previous level, $A[1-x]$. We may write:

$$
\left[D-D^{\prime}\right] / D=[x M / n] .[1-x[1-M / n]]
$$

The scale of the reduction in the size of lump sum is tabulated in Table 2 . As is evident from the Table, the

Table 2:

Reduction in the lump sum of damages required to preserve after tax income at its original level when capital repayment element of annuity income is tax exempt

\begin{tabular}{|c|c|cc|}
\hline $\begin{array}{c}\text { Years of } \\
\text { loss } \\
n\end{array}$ & $\begin{array}{c}\text { Multiplier } \\
(r=4 \% \mathrm{pa})\end{array}$ & $x=0.25$ & Tax rate \\
\hline 5 & $M$ & 0.2289 & $x=0.40$ \\
10 & 4.4518 & 0.2128 & 0.3725 \\
15 & 8.1109 & 0.1981 & 0.3510 \\
20 & 11.1183 & 0.1847 & 0.3307 \\
\hline
\end{tabular}

reduction is in the 18 to $23 \%$ range when income is taxed at $25 \%$ and $31 \%$ to $37 \%$ when the tax rate is $40 \%$. It is perhaps worth noting that the same adjustments could be made via the Multiplier rather than via the annual post-tax loss.

It should be noted also that the picture is somewhat different in the event that the structured settlement contains an escalation clause under which nominal payments increase at a fixed rate (of, say, $5 \%$ pa) or under which nominal payments are indexed to an inflation measure such as RPI. The adjustment is of the order of $16 \%$ rather than $18 \%$ in the case of a loss stretching over 20 years.

\subsection{The insurer's discount}

One of the grounds used by UK insurers for charging a discount on structured settlements is that they incur a disruption to their cash flow position. The disruption is caused by their having to make payments of tax to the Inland Revenue in respect of all income they pay out as annuities. The tax relief allowed on the capital repayment component of annuities they can recover subsequently only when making future payments of tax. Without more information on the timing of these various payments and offsets it is not possible to estimate the opportunity cost of the foregone cash flow. It seems unlikely, on the face of it, that these disadvantages are very great. 
Nevertheless the point is of interest if only because in the present debate of the matter in the UK there are those who argue that England should switch to the US system under which life offices are apparently able to make annuity payments to plaintiffs gross of tax (Law Commission, 1992). This would be of further benefit to plaintiffs, who would get a larger annuity from the lump sum since a discount need no longer be payable, and to insurers who would no longer face a cash flow disruption.

\subsection{Structuring and efficiency}

When the insurance company quotes terms for a structured settlement it may endeavour to appropriate the tax gain by charging a 'discount' against the sum of damages. The insurance company is likely to be in a strong position at this point because the plaintiff would, by refusing to pay the discount, be forced into a non-structured solution and the tax gain would be lost to all. Interestingly reinsurance companies have criticized this practice of charging discounts, presumably because the insurer is appropriating the tax gain and passing on the full cost (including that of the 'discount') to the reinsurer.

From an efficiency point of view the discount may have little significance in the short run. The costs to insurers of meeting claims are passed onto motorists, employers or participants in whatever class of accident-generating activity we are considering. If awards of damages remain the same but insurers are able to claw back some tax advantages the costs they are passing to insureds will remain the same and thus the structure of premiums can remain the same also. But such a position may not be sustainable in the longer run if the insurance industry is competitive. Insurers who successfully appropriate discounts from plaintiffs may be able to attract more business by reducing their premiums and thus the windfall profits from the tax change will get bid away and premiums will fall.

This is the point, from an efficiency perspective, at which the problems begin. If awards of damages were previously at the efficient level, the tax change will result in reduced insurance premium costs and thus causing accidents will become 'too cheap'. Some of the costs of accidents will spread to the taxpayer who is now subsiding the activities of those who cause accidents. [A similar argument is developed in a different context by Bishop and Kay (1987)]. A tax change intended to benefit plaintiffs may thus end up giving rise to an accident rate which is higher than previously. This prognosis differs sharply from that of Inland Revenue, a senior officer of which has referred to 'the economic and social advantages of structuring'; Newstead (1989).

\section{4. 'Bottom-up' settlements}

In the analysis in earlier sections it was implicitly assumed that judges have no problem in translating between annual loss and lump sums of damages via the multiplier. This is equivalent to arguing that judges are adept both at estimating the time path of a plaintiff's loss and at putting a valuation on the loss. In practice, however, the valuation process does not always follow this idealised pattern.

Our model is not, however, sufficiently general to enable us to say whether the previous level of accidents was optimal. From our "compensatory" perspective we can do no more than contemplate the possibility of change in the overall level of damages and in the source of its funding.

Structured settlements, in principle, offer an excellent opportunity for a high degree of matching the plaintiff's loss. Once the time path of loss has been established, it becomes 
possible to specify a bundle of annuities which will generate a perfect correspondence with the structure of loss. The bundle of annuities in question can then be valued by the insurance market, thereby ensuring that the plaintiff is correctly compensated in terms of the replacement income stream.

Insurers will need to buy financial instruments in order to meet their obligations under a structured settlement. The costs of these instruments, and thus of the bundles of annuities which comprise the structures, fluctuate from day to day as expectations about future price inflation and nominal interest rates and other variables change. The costs fluctuate also as insurers, in what is a relatively specialist market, seek to adjust their risk portfolio positions. This is tantamount to arguing that the discount rate from which the court calculates the multiplier also fluctuates daily.

There are two possible solutions to this. One is to use a discount rate which over a number of years is close to the average observed rate. But a superior solution might be to argue that courts do not need to concern themselves with this matter at all since the insurance market is itself a place where complex valuations of exactly the right sort are being made daily. Furthermore, the discount rate does not need to be averaged or approximated since the market will reveal an appropriate overall rate which reflects expectations as to the term structure of interest rates over the relevant time horizon.

Elsewhere the term 'decoupling' has been used to refer to the possibility of keeping quite distinct the 'identification of loss' stage in the process and the 'valuation' stage; Law Commission (1992). By splitting the process into two in this way it is possible to exploit both the experience of the judiciary in assessing the nature of loss and the financial markets in constructing and valuating instruments to meet the loss.

The drawback of the averaging approach is that the courts will decide upon the time path of loss and apply a multiplier which is based on an assumption about the long run average discount rate which may be at odds with prevailing market rates. The sum of damages will then only by remote coincidence be the right amount needed to buy a set of annuities which together produce an income stream to match the plaintiff's loss. In general the sum of damages will be either higher or lower than the market price for replacing the plaintiff's loss. Settlement structures designed to match the time path of loss, rather than to absorb the previously-decided amount of damages in a convenient way, are referred to as 'bottom-up' settlements. They are, apparently, rather uncommon.

\section{Concluding remarks}

Structured settlements have become relatively popular in England since the agreement in 1987 between the Association of British Insurers and the Inland Revenue to exempt from income tax the capital repayment element of plaintiffs' income from annuities. This rapid growth can be explained by the enthusiasm on the part of defendants' insurers for a system under which they are able to appropriate via a 'discount' a significant part of the tax saving which was intended to benefit plaintiffs. It is an enthusiasm however which is tempered by the disadvantages which flow from the cash flow interruption and from the insurer's fears that the tax position may change at some point in the future.

We have argued in this paper that Structured Settlements, to the extent that they involve a 'bottom-up' calculation of the structure of plaintiff's losses, represent a good starting point for the assessment of damages. Further, we have argued that it would be rational for the court to take advice on the valuation of loss from the financial markets, rather 
than apply thcir own rather impressionistic methods. The main drawback to this solution is the role of the 'discount' which seems to be an inevitable consequence of allowing the defendant's insurer to put together the structure. But this is a separable issue: it is a conscquence of the creation of a tax excmpt class of income. It is thus a problem which could be resolved by discontinuing the tax exemption on any ncw structures without influencing the attractions for plaintiffs of structured settlements. The real problcm is that getting rid of the tax excmption would also destroy the incentives insurcrs have for offering structures.

It remains to be established empirically whether the advent of structural settlements in England has had the effect of rcducing the valuc of awards of damages. There remains considerable scope also for the dcvelopment of models combining the deterrence and compensatory aspects of negligence rules. This paper has indicated that the English judiciary can easily run into difficultics when computing the present valuc of loss suffered by plaintiffs. When combined with an incompletely thought out tax changc this can produce a situation wherc it is rather unlikely that objectives are being met either from a compensatory point of view of from a deterrence perspective.

\section{REFERENCES}

ARAK, M. and KREICHER, L. (1985) The Real Rate of Interest: Inferences from the New UK Indexed Gilts, International Economic Review, 25, 2, 399-408.

BISHOP, W. and KAY, J. (1987) Taxation and Damages: The Rule in Gourley's Case, Law Quarterly Review, 103, 220.

BOWLES, R. (1981) Economic Aspects of Legal Procedure, in P. Burrows and C. Veljanovski (Eds), The Economic Approach to Law, Butterworths, London.

GENN, H. (1988) Hard Bargaining: Out of Court Settlement in Personal Injury Actions, Oxford University Press.

HIRSHLEIFER, J. and RILEY, J. G. (1992) The Analytics of Uncertainty and Information, Cambridge University Press.

KEMP and KEMP, The Quantum of Damages, Sweet and Maxwell.

LAW COMMISSION (1992) Structured Settlements and Interim and Provisional Damages, Consultation Paper No. 125, Law Commission, HMSO, London.

LEVIN, E.J. and COPELAND, L.S. (1992) Reading the Message from the UK Indexed Bond Market: Real Interest Rates, Expected Inflation and the Risk Premium, Discussion Paper 92/8, Department of Economics, University of Stirling.

NEWSTEAD, M. (1989) Tax Aspects of Structured Settlements, The Litigation Letter, 7, 10, 78.

PEARSON COMMISSION (1978) Report of the Royal Commission on Civil Liability and Compensation for Personal Injury, Cmnd. 7054, HMSO, London.

PHILIPS, J., HAWKINS, K. and FLEMMING, J. (1975) Compensation for Personal Injuries, Economic Journal, 85, 129-134.

PREVETT, J. H. (1986) Actuarial Assessment of Damages, Chapter 6 in D. Kemp (Ed), Damages for Personal Injury and Death, 3rd Edition, Longman Professional.

REA, S. (1990) Taxation, the Standard of Care and Damage Awards, International Review of Law and Economics, 10 (3), December 1990, 285-292.

SHAVELL, S. (1987) Economic Analysis of Accident Law, Harvard University Press. 